\title{
BMJ Open Risk of poor mental health and experience of violence among a young adult population with same-sex sexuality: a cross-sectional study in southern Sweden
}

\author{
Charlotte Agardh (D) , ${ }^{1,2}$ Benedict Oppong Asamoah (D) , ${ }^{1}$ Tobias Herder (D) , \\ Markus Larsson ${ }^{1}$
}

To cite: Agardh C, Asamoah BO, Herder T, et al. Risk of poor mental health and experience of violence among a young adult population with same-sex sexuality: a cross-sectional study in southern Sweden. BMJ Open 2022;12:e052617. doi:10.1136/ bmjopen-2021-052617

- Prepublication history for this paper is available online. To view these files, please visit the journal online (http://dx.doi. org/10.1136/bmjopen-2021052617).

Received 10 June 2021 Accepted 13 January 2022

Check for updates

(C) Author(s) (or their employer(s)) 2022. Re-use permitted under CC BY-NC. No commercial re-use. See rights and permissions. Published by BMJ.

${ }^{1}$ Dept of Clinical Sciences, Social Medicine and Global Health, Lund University, Malmö, Sweden ${ }^{2}$ Borgholm Health Care Center, Kalmar County Council, Kalmar, Sweden

Correspondence to Dr Charlotte Agardh; charlotte.agardh@gmail.com

\section{ABSTRACT}

Objectives To assess prevalence and correlates of samesex sexuality and its relationship to poor mental health and experiences of violence among youth and young adults in Sweden. A secondary aim was to estimate the same-sex sexuality attributable fractions.

Design A population-based cross-sectional survey.

Setting Southern Sweden.

Participants 2968 respondents out of 7000 youth and young adults between 18 and 29 years old, resident in southern Sweden, selected randomly by the Swedish Central Population Registry (final sample $=2931$ respondents, 318 with same-sex sexuality and 2613 without)

Outcome measures The outcome measures were selfreported poor mental health (depression and anxiety) and experience of violence (physical violence, sexual violence and sexual coercion).

Results Increased odd of high scores of depression (adjusted OR 1.8, 95\% $\mathrm{Cl} 1.39$ to 2.26 ) and anxiety (adjusted OR 1.6, 95\% Cl 1.28 to 2.07) were observed among youth and young adults with same-sex sexuality. Similarly, increased odds of experience of physical violence (OR 1.8, 95\% $\mathrm{Cl} 1.23$ to 2.51), sexual violence (OR 2.8, 95\% Cl 1.96 to 3.89 ) and sexual coercion (OR $2.5,95 \% \mathrm{Cl} 1.95$ to 3.30 ) were observed with same-sex sexuality. Within the entire young population, samesex sexuality accounted for $4.7 \%$ and $4.1 \%$ of the self-reported experience of depression and anxiety, respectively. The estimated same-sex sexuality attributable fractions of violence within the entire population of young people were $4.5 \%$ for physical violence, $7.3 \%$ for sexual violence and $6.4 \%$ for sexual coercion.

Conclusions This study findings suggest that same-sex sexuality is associated with poor self-rated mental health and experience of violence among youth and young adults in Sweden. Some differences were observed between males and females, indicating that the vulnerabilities and experiences vary between young males and females. Further research is needed in order to gain a deeper knowledge of the factors underlying these associations and the gender differences observed.

\section{Strengths and limitations of this study}

- This was a cross-sectional study based on selfreported, retrospective, information and as such creates a potential risk for recall bias, which could result in error due to misclassification of measured variables.

- However, some items in the questionnaire referred to present experiences or recent exposure, for example, by specifying 'during the last 12 months' which possibly could minimise recall error, but this was not the case for all items.

- Same-sex sexuality is measured in this study and included experience of same-sex sexual behaviour and homosexual or bisexual orientation in order to capture a broader group.

- Mental health was measured by a previously validated self-rating instrument, Hopkins Symptom Checklist 25 and a high score of poor self-rated mental health, indicating symptoms of depression or anxiety, is not equivalent to fulfilling the criteria of a formal diagnosis.

\section{INTRODUCTION}

Population-based studies in Sweden have shown that $0.7 \%-0.8 \%$ of adult respondents self-identified as lesbian/gay and 1.2\%-1.8\% as bisexual. ${ }^{1}$ However, studies among youth in Sweden have yielded higher proportions of lesbian, gay or bisexual (LGB) identities ${ }^{2-5}$ and the figure regarding same-sex sexual behaviour might be even higher, as not everyone who engages in sexual relationships with someone of the same sex identifies themselves as LGB. ${ }^{3}$ Previous research indicates that the LGB population has elevated risks of mental illness, especially depression, anxiety and suicidal behaviour, compared with the general population. ${ }^{6-10}$ The disparities in mental health are in part due to stress related to the stigma (ie, minority stress) to which 
LGB people are exposed, such as discrimination, social isolation and expectation and experience, of rejection and violence. ${ }^{11}$ This, in turn, increases risks of psychological stress reactions, for example, reduced mental well-being and suicidal behaviour. ${ }^{101213}$ Bränström in a populationbased longitudinal study of 30730 individuals found that Swedish LGB identified respondents were twice as likely to receive treatment for anxiety disorders and more likely to medicate with antidepressants, compared with the general population. ${ }^{8}$ In another Swedish populationbased study, Björkenstam et al demonstrated similar results, showing that bisexual women and gay men were more likely to report anxiety, being diagnosed with depression, and medicating against anxiety and depression than the heterosexual population. ${ }^{9}$ In Norway, Wichstrøm and Hegna found that youth reporting experience of same-sex sexual behaviour were more likely to attempt suicide in comparison to youth with no such behaviour. ${ }^{14}$ Research in Sweden has further demonstrated higher levels of co-occurrence of alcohol and drug use and psychological distress among gay and bisexual persons (but not among lesbian women), compared with the general population. ${ }^{1}$ However, despite these results, few studies have focused specifically on mental health of the younger strata of LGB identified persons or those engaging in same-sex sexual relationships.

Violence, including physical and sexual violence, is a major global public health concern and may particularly affect LGB identified persons and those who engage in same-sex sexual relations and could at least partly explain the high levels of poor mental health within these populations. ${ }^{815}$ Stigma and marginalisation are some of the factors that have been attributed to the increased risk for victimisation among LGB people. ${ }^{16}$ In Sweden, it has previously been found that non-heterosexually identified youth aged 18 years and older were more likely to report victimisation due to both physical violence and sexual abuse compared with heterosexually identified youth. ${ }^{15}$ Bränström et al found that homoexually and bisexually identified males and females were at significantly increased risk of being victims of physical violence during the last 12 months preceding the study. ${ }^{17}$ The results from a nationwide survey focusing on sexual and reproductive health and rights among Swedish youth revealed that $30 \%$ of lesbians and $10 \%$ of gay men have been exposed to violence, compared with $11 \%$ and $1 \%$ among women and men, respectively, in the general population. ${ }^{18}$ Research has also shown that negative experiences of 'coming out' (ie, informing about one's sexual orientation/identity), for example, a family member's rejection, also increase the risk of alcohol and substance abuse, as well as negative effects on the mental and psychosocial health. ${ }^{12} 19{ }^{20}$ Yet, there is a scarcity of research about the types of violence and their consequences among youth and young adults with same-sex sexuality. ${ }^{21} 22$

The aim of this study was to assess prevalence and correlates of same-sex sexuality and its relationship to (1) poor mental health and (2) experiences of violence among youth and young adults in Sweden. A secondary aim was to estimate the same-sex sexuality attributable fractions (AF) of both poor self-rated mental health and experience of violence among those with same-sex sexuality and in the total population of youth and young people in Sweden. The concept of same-sex sexuality used in this study refers to persons who either selfidentify as homosexual/bisexual or engage in sexual/ romantic behaviour with persons of the same sex, regardless of whether they identify as LGB or not. Findings from this study may inform future interventions that seek to address the health and social conditions among people with same-sex sexuality.

\section{METHOD \\ Study design}

This was a cross-sectional study based on data collected in 2013 in Skåne, a county in the most southern part of Sweden with a population of almost 1.3 million. The structured survey questionnaire was developed from previously used and validated questions. ${ }^{4324}$

\section{Patient and public involvement}

No patients were involved in the study. The public was involved in an early phase of methodological development. Focus group discussions were held with representatives from the study population in order to identify relevant research questions and meaningful outcome measures. Knowledge gained from these efforts helped to inform the design of the questionnaire. The questionnaire was then pretested in additional focus group discussions.

The public was not involved in any further phases of the study and did not participate in the recruitment of the study participants or in the plans for the dissemination of the study findings.

\section{Participants and data collection}

The data that this study used were obtained from a population-based survey study of 7000 youth and young adults between 18 and 29 years old, selected randomly by the Swedish Central Population Registry. All respondents had permanent residence in Skåne as of 1 January 2013. Selected participants received an invitation letter with information concerning the study and that participation was voluntary and anonymous. They also received a link in order to access an online version of the questionnaire. Reminders were sent out three times, and a printed version of the questionnaire was sent out together with the last reminder to those who had not yet responded. Those who participated received a cinema ticket as compensation for the time spent answering the questionnaire.

The questionnaire contained 79 self-reported questions and included items regarding socio-demographic factors, mental health, sexual risk-taking behaviour, physical and sexual violence, sensation seeking and use of drugs and alcohol. For both the online and paper versions of 
the questionnaire, the questions were adaptive, organised hierarchically with contingent branching to display relevant survey items based on previous responses, and allowed respondents to navigate through the questionnaire with ease. The measures used in the current study are described below.

\section{Study sample}

A total of 2968 individuals responded to the questionnaire, which gave a response rate of $45 \%$. Figures on the completion rate for the entire survey is unknown to this study. However, out of the 2968 respondents, 37 had missing responses on questions related to sexuality and were thus excluded from further analysis because their experience of same-sex sexuality could not be determined. Thus, the final sample used in the analyses was 2931, which comprised 318 respondents who reported same-sex sexuality (index group: with experience of same-sex sexual relation and/or homosexual or bisexual orientation) and 2613 respondents who reported no same-sex sexuality (reference group).

\section{Main independent variable}

Same-sex sexuality was assessed by combining two separate measures, that is, self-identified sexual orientation and experience of same-sex sexual relations.

Experience of same-sex sexual relations was assessed by the question 'If you think of people you have had sexual relations with, what gender are they?'. The response alternatives for this variable were: 'always female', 'usually female but sometimes male', 'equally between male/ female', 'usually male but sometimes female' and 'always male'. This variable was dichotomised as 'no' if the answer was always the opposite gender and 'yes' for all other alternatives. Sexual orientation was assessed by how the respondent self-identified their sexual orientation and the alternatives were: 'heterosexual', 'homosexual', 'bisexual' and 'none of the alternatives'. This variable was then dichotomised as 'same-sex sexual orientation' if the answer was homosexual or bisexual orientation and 'no same-sex sexual orientation' for all other alternatives. Same-sex sexuality was then assessed by combining those respondents who had reported experiences of same-sex sexual relations and/or reported same-sex sexual orientation.

\section{Other covariates}

According to the United Nation Definition of youth ${ }^{25} 26$ age was dichotomised into two age groups; 18-24 years representing youth, and 25-30 years representing older persons, that is, young adults.

Sex was classified as male or female.

Level of parents' education was used to assess participants' socioeconomic status since the younger age group might not have finished their education or were unemployed at the time of the questionnaire. Level of parents' education is a validated predictor of the educational and occupational outcome among the younger population. ${ }^{27}$
The response alternatives were: '9-year compulsory school', '2 years of upper secondary school', '3-4 years of upper secondary school', 'other types of schools' and 'university'. The variable was then dichotomised as 'High level of education' if one or both parents had a university education and all other alternatives as 'low level of education'.

\section{Dependent variables}

Mental health

Mental health was measured by the validated instrument Hopkins Symptom Checklist 25 (HSCL-25). ${ }^{24} 28$ This screening instrument consists of 25 self-reported items divided into 15 items assessing symptoms of depression and 10 items assessing symptoms of anxiety. Each question had four response options corresponding to a scale from 1 to 4 ('not at all' $=1$ to 'extremely' $=4$ ), indicating how much the symptom bothered them during the last 30 days. The mean score of symptoms of depression and anxiety were separately compiled by the total scores for each measure divided by the number of items answered. The cut-off points of high vs low scores for respective measure (anxiety and depression) were determined on the basis of a median split of the distribution of the mean scores. As the distribution of median scores differed between males and females, the median was calculated separately by gender. Scores above the median was dichotomised as 'high scores of depression' and scores below the median as 'low scores of depression'. Dichotomisation of anxiety symptom scores was derived by the same method as depression.

\section{Violence}

Violence was measured by three questions concerning physical violence, sexual violence and sexual coercion.

Physical violence and sexual violence were assessed by two different questions, that is, 'Have you been exposed to physical violence during the last 12 months?', and 'Have you been exposed to sexual violence during the last 12 months?'. Physical violence had 'yes' and 'no' as response alternatives and was dichotomised accordingly. Sexual violence had the response alternatives: 'Yes', and 'No, not during the last 12 months but I have a previous experience' and 'No'. The first two alternatives were dichotomised as 'experience of sexual violence' and the third response alternative 'No' as 'no experience of sexual violence'.

Sexual coercion was determined by an instrument used in a number of previous studies in Sweden and elsewhere. ${ }^{29-31}$ This instrument contains the following response alternatives: 'You have been forced to show your sexual organ', 'Someone has forced you to let them touch your sexual organ', 'Someone forced you to let them suck or lick your sexual organ', 'Someone has forced you to let them show you their own sexual organ', 'You have been forced to watch someone masturbate', 'You have been forced to masturbate someone', 'You have been forced to take part in oral sex or to lick someone's sexual organ', 
'You have been forced to take part in sexual intercourse with the penis in the vagina, or someone has inserted an object into your vagina', 'You have been forced to take part in sexual intercourse with the penis in the anal, or someone as inserted an object into your anal' and 'You have been forced to pose for a sex photo or sex film'. The measure was dichotomised as 'Experience of sexual coercion' if the respondent had a positive response to at least one of the items, and 'no experience of sexual coercion' if all answers were negative.

\section{Statistical analysis}

Statistical analyses were performed by using Stata V.12.0. As a first step, prevalence for the different variables was determined and stratified by gender to examine prevalence differences across gender using $\chi^{2}$ tests with accompanying $p$ values. Potential associations between the independent and dependent variables were also examined by $\chi^{2}$ tests. As a second step, simple logistic regression analyses were performed in order to determine crude ORs with $95 \%$ CIs for the associations between same-sex sexuality and poor mental health and experience of violence, respectively. Multiple logistic regression analyses were performed with adjustment for the potential confounders age, gender and level of parents' education. Persons with missing values for at least one of the variables used for the model were excluded from the analysis. Significance was accepted at $\mathrm{p} \leq 0.05$, two-tailed.

\section{Estimation of same-sex sexuality AF of poor self-reported mental} health and violence among youth and young people in Sweden We estimated AF of poor self-reported mental health and violence among youth and young adults with same-sex sexuality $(\mathrm{AF})$ and in the total population $\mathrm{AF}(\mathrm{PAF})$. The $\mathrm{AF}$ and PAF were calculated to estimate the excess risk of the outcome experienced by young people with same-sex sexuality as a result of their status. This gives the proportion of the poor self-rated mental health and experience of violence that could be avoided within the group with same-sex sexuality (ie, AF; among group with same-sex sexuality) and in the entire population of youth and young adults in Sweden (ie, PAF; in the total population) if the risk of the outcome attributed to same-sex sexuality is prevented. This is based on the assumption of a causal link between same-sex sexuality and experience of poor self-reported mental health and/or violence.

The logistic regression-based AF among young people with same-sex sexuality (stratified by gender) was calculated as:

$$
\mathrm{AF}=100(\mathrm{OR}-1) / \mathrm{OR}
$$

The stratum-specific PAF (sPAF) was then computed using the equation:

$$
\mathrm{sPAF}=\mathrm{P} * \mathrm{AF}=100 \mathrm{P} *(\mathrm{OR}-1) / \mathrm{OR}
$$

where OR is generated from multiple logistic regression analyses and $\mathrm{P}$ is the proportion of young people with same-sex sexuality (estimated separately for males and females). The overall PAF was estimated by combining the sPAF for both males and females.

In order to ensure respondents' anonymity, the national identification numbers of respondents and questionnaires were stored at different locations while the collection of data was ongoing, and as soon as the collection of data was completed, the archive with identification numbers was destroyed. Furthermore, the answers from the electronic questionnaire were stored on a secured server that was inaccessible to third parties. The participants also received information regarding contact details in case they had questions or needed to talk to someone before or after completing the questionnaire.

\section{RESULTS}

Table 1 shows characteristics of the total sample of respondents $(n=2968)$ regarding sociodemographic factors and same-sex sexuality, stratified by gender. The majority of respondents were females $(58.5 \%$ females vs $41.5 \%$ males) and $60.5 \%$ of the respondents were within the age group $18-24$ years and $39.5 \%$ in the age group 25-30 years. A total of $8 \%$ reported having experience of same-sex sexual relationships, and $7.1 \%$ reported their sexual orientation as either homosexual or bisexual. Thus, a total of $10.8 \%(\mathrm{n}=318)$ reported same-sex sexuality (ie, experience of same-sex sexual relation and/or homo- or bisexual orientation), with a notably higher prevalence of $12.7 \%$ among females in comparison with $8.2 \%$ among males.

Table 2 shows the distribution of socio-demographic factors, mental health and violence among youth and young adults with no same-sex sexuality and those with same-sex sexuality, stratified by gender. Among respondents who reported same-sex sexuality, $68.4 \%$ were females and $31.6 \%$ were males. A total of $58.1 \%$ were in the age group 18-24 years and $41.9 \%$ in the age group 25-30 years. Lower parental educational level was reported among $45.1 \%$ respondents with same-sex sexuality compared with $39.3 \%$ respondents with no same-sex sexuality. No significant difference between the genders were found with regard to age group and parental educational level. A higher prevalence of poor self-rated mental health (depression and anxiety) and experience of violence (experience of physical violence, sexual violence and sexual coercion) was found among respondents who reported same-sex

\section{Mental health}

In the simple logistic regression model (table 3), reporting same-sex sexuality was significantly associated with high scores of depression (OR 1.7, 95\% CI 1.36 to 2.19) and anxiety (OR 1.8, 95\% CI 1.43 to 2.32). When stratified by gender, however, differences were observed between males and females. Males with same-sex sexuality had significantly increased odds for high depression scores (OR 1.8, 95\% CI 1.32 to 2.36), but not for anxiety. Females with same-sex sexuality had significantly increased odds 
Table 1 Distribution of sociodemographic factors, sexual behaviour, sexual orientation and same-sex sexuality among youth and young adults in Sweden $(n=2968)$

\begin{tabular}{|c|c|c|c|c|c|c|c|}
\hline & \multicolumn{2}{|l|}{ All } & \multicolumn{2}{|l|}{ Male } & \multicolumn{2}{|c|}{ Female } & \multirow[b]{2}{*}{ P value $^{*}$} \\
\hline & $\mathbf{n}$ & $\%$ & $\mathrm{n}$ & $\%$ & $\mathbf{n}$ & $\%$ & \\
\hline \multicolumn{8}{|l|}{ Sex } \\
\hline Male & 1228 & 41.5 & & & & & \\
\hline Female & 1733 & 58.5 & & & & & \\
\hline (Missing) & (7) & & & & & & \\
\hline Age & & & & & & & 0.890 \\
\hline $18-24$ & 1774 & 65.6 & 738 & 60.6 & 1036 & 60.3 & \\
\hline $25-30$ & 1161 & 34.4 & 480 & 39.4 & 681 & 39.7 & \\
\hline (Missing) & (26) & & (10) & & (16) & & \\
\hline Parental educational level & & & & & & & 0.695 \\
\hline High & 1764 & 60.1 & 727 & 59.7 & 1036 & 60.4 & \\
\hline Low & 1170 & 39.9 & 491 & 40.3 & 679 & 39.6 & \\
\hline (Missing) & (34) & & (10) & & (18) & & \\
\hline Experience of same-sex relation & & & & & & & $<0.001$ \\
\hline No & 2563 & 92.0 & 1083 & 94.3 & 1480 & 90.4 & \\
\hline Yes & 224 & 8.0 & 65 & 5.7 & 158 & 9.6 & \\
\hline (Missing) & $(181)$ & & (80) & & (95) & & \\
\hline Homosexual or bisexual orientation & & & & & & & 0.053 \\
\hline No & 2710 & 92.9 & 1142 & 94.0 & 1568 & 92.1 & \\
\hline Yes & 208 & 7.1 & 73 & 6.0 & 134 & 7.9 & \\
\hline (Missing) & (50) & & (13) & & (31) & & \\
\hline $\begin{array}{l}\text { Same-sex sexuality (experience of same- } \\
\text { sex relation and homosexual or bisexual } \\
\text { orientation) }\end{array}$ & & & & & & & $<0.001$ \\
\hline No & 2613 & 89.2 & 1116 & 91.8 & 1497 & 87.3 & \\
\hline Yes & 318 & 10.8 & 100 & 8.2 & 217 & 12.7 & \\
\hline (Missing) & (37) & & (12) & & (19) & & \\
\hline
\end{tabular}

${ }^{*} P$ value was produced by $\chi^{2}$ test and represents statistical significance level, $p \leq 0.05=$ significant

for high depression scores (OR 1.8, 95\% CI 1.32 to 2.37) and for high anxiety scores (OR $1.8,95 \%$ CI 1.35 to 2.44 ) (table 3).

After adjustment for age and parental education in table 4 , the findings of significantly increased odds for high depression scores (adjusted OR 1.8, 95\% CI 1.39 to 2.26) and high anxiety scores (adjusted OR $1.6,95 \% \mathrm{CI}$ 1.28 to 2.07$)$ remained in the total sample. Similar to the unadjusted model, the association between same-sex sexuality and high scores of depression remained significant among both males and females in the adjusted model. Moreover, increased odds for high scores of anxiety among females also remained significant after adjustment (table 4).

\section{Violence}

Same-sex sexuality was significantly associated with physical violence (OR 1.8, 95\% CI 1.26 to 2.49), sexual violence (OR 3.2, 95\% CI 2.29 to 4.37) and sexual coercion (OR 2.8, 95\% CI 1.15 to 3.55 ) in the unadjusted model (table 3). When exploring gender differences, males who reported same-sex sexuality had significantly increased odds of experiencing physical violence (OR $1.9,95 \%$ CI 1.12 to 3.25 ), sexual violence (OR 9.2, 95\% CI 3.36 to 25.35 ) and sexual coercion (OR 4.7, 95\% CI 2.94 to 7.44). Similarly, among females, significant associations were found with physical violence (OR $1.9,95 \%$ CI 1.12 to 2.91 ), sexual violence (OR 2.5, $95 \%$ CI 1.76 to 3.58 ) and sexual coercion (OR 2.0, 95\% CI 1.51 to 2.76 ) (table 3 ).

In table 4 (adjusted models), the significantly increased odds of experience of physical violence (OR 1.8, 95\% CI 1.23 to 2.51 ), sexual violence (OR 2.8, 95\% CI 1.96 to 3.89 ) and sexual coercion (OR 2.5, 95\% CI 1.95 to 3.30 ) among respondents with experience of same-sex sexuality persisted. When stratified by gender, the increased odds of physical violence remained significant among males with same-sex sexuality were no longer significant 
Table 2 Distribution of sociodemographic factors, mental health, violence and sexual behaviour among youth and young adults with no same-sex sexuality $(n=2613)$ and with same-sex sexuality $(n=318)$, in Sweden

\begin{tabular}{|c|c|c|c|c|c|c|c|c|c|c|c|c|c|c|}
\hline & \multicolumn{7}{|c|}{ No same-sex sexuality } & \multicolumn{7}{|c|}{ Same-sex sexuality } \\
\hline & \multicolumn{2}{|l|}{ All } & \multicolumn{2}{|c|}{ Males } & \multicolumn{2}{|c|}{ Female } & \multirow[b]{2}{*}{ P value* } & \multicolumn{2}{|l|}{ All } & \multicolumn{2}{|c|}{ Male } & \multicolumn{2}{|c|}{ Female } & \multirow[b]{2}{*}{ P value* } \\
\hline & $\mathbf{n}$ & $\%$ & $\mathbf{n}$ & $\%$ & $\mathbf{n}$ & $\%$ & & $\mathbf{n}$ & $\%$ & $\mathbf{n}$ & $\%$ & $n$ & $\%$ & \\
\hline \multicolumn{15}{|l|}{ Sex } \\
\hline Male & 1116 & 42.7 & & & & & & 100 & 31.6 & & & & & \\
\hline Female & 1497 & 57.3 & & & & & & 217 & 68.4 & & & & & \\
\hline (Missing) & (0) & & & & & & & (1) & & & & & & \\
\hline Age & & & & & & & 0.994 & & & & & & & 0.761 \\
\hline $18-24$ & 1576 & 60.7 & 673 & 60.7 & 903 & 60.7 & & 180 & 58.1 & 58 & 59.2 & 121 & 57.3 & \\
\hline $25-30$ & 1019 & 39.3 & 435 & 39.3 & 584 & 39.3 & & 130 & 41.9 & 40 & 40.8 & 90 & 42.7 & \\
\hline (Missing) & (18) & & (8) & & (10) & & & (8) & & (2) & & (6) & & \\
\hline $\begin{array}{l}\text { Parental educational } \\
\text { level }\end{array}$ & & & & & & & 0.669 & & & & & & & 0.689 \\
\hline High & 1576 & 60.7 & 668 & 60.2 & 908 & 61.1 & & 169 & 54.9 & 52 & 53.1 & 116 & 55.5 & \\
\hline Low & 1020 & 39.3 & 441 & 39.8 & 579 & 38.9 & & 139 & 45.1 & 46 & 46.9 & 93 & 44.5 & \\
\hline (Missing) & $(17)$ & & (7) & & (10) & & & (10) & & (2) & & (8) & & \\
\hline Depression & & & & & & & 0.535 & & & & & & & 0.582 \\
\hline Low scores & 1414 & 54.3 & 611 & 55.1 & 803 & 53.8 & & 128 & 40.8 & 43 & 43.0 & 85 & 39.7 & \\
\hline High scores & 1188 & 45.7 & 499 & 44.9 & 689 & 46.2 & & 186 & 59.2 & 57 & 57.0 & 129 & 60.3 & \\
\hline (Missing) & (11) & & (6) & & (5) & & & (4) & & (0) & & (3) & & \\
\hline Anxiety & & & & & & & 0.793 & & & & & & & 0.425 \\
\hline Low scores & 1489 & 57.2 & 632 & 56.9 & 857 & 57.4 & & 144 & 45.7 & 49 & 49.0 & 95 & 44.2 & \\
\hline High scores & 1115 & 42.8 & 479 & 43.1 & 636 & 42.6 & & 171 & 54.3 & 51 & 51.0 & 120 & 55.8 & \\
\hline (Missing) & (9) & & (5) & & (4) & & & (3) & & (0) & & (2) & & \\
\hline $\begin{array}{l}\text { Experience of } \\
\text { physical violence }\end{array}$ & & & & & & & 0.001 & & & & & & & 0.136 \\
\hline No & 2380 & 91.2 & 991 & 89.0 & 1389 & 92.8 & & 269 & 85.4 & 81 & 81.0 & 187 & 87.4 & \\
\hline Yes & 230 & 8.8 & 122 & 11.0 & 108 & 7.2 & & 46 & 14.6 & 19 & 19.0 & 27 & 12.6 & \\
\hline (Missing) & (3) & & (3) & & (0) & & & (3) & & (0) & & (3) & & \\
\hline $\begin{array}{l}\text { Experience of sexual } \\
\text { violence }\end{array}$ & & & & & & & $<0.001$ & & & & & & & $<0.001$ \\
\hline No & 2430 & 93.4 & 1104 & 99.2 & 1326 & 89.1 & & 259 & 81.7 & 93 & 93.0 & 165 & 76.4 & \\
\hline Yes & 172 & 6.6 & 9 & 0.8 & 163 & 10.9 & & 58 & 18.3 & 7 & 7.0 & 51 & 23.6 & \\
\hline (Missing) & (11) & & (3) & & (8) & & & (1) & & (0) & & (1) & & \\
\hline $\begin{array}{l}\text { Experience of sexual } \\
\text { coercion }\end{array}$ & & & & & & & $<0.001$ & & & & & & & 0.371 \\
\hline No & 1685 & 74.2 & 786 & 85.3 & 899 & 66.7 & & 145 & 51.1 & 47 & 55.3 & 98 & 49.5 & \\
\hline Yes & 585 & 25.8 & 136 & 14.7 & 449 & 33.3 & & 139 & 48.9 & 38 & 44.7 & 100 & 50.5 & \\
\hline (Missing) & (343) & & (194) & & (149) & & & (34) & & (15) & & (19) & & \\
\hline
\end{tabular}

Sexuality, in comparison with respondents who reported no same-sex sexuality.

${ }^{*} \mathrm{P}$ value was produced by $\chi^{2}$ test and represents statistical significance level, $p \leq 0.05=$ significant

for females with same-sex sexuality when adjusted for the confounders. The statistically significant association between same-sex sexuality and sexual violence and sexual coercion persisted among both males and females (table 4).

\section{Estimation of same-sex sexuality AF of self-reported poor} mental health

Table 5 shows the same-sex sexuality AF and PAF of poor self-reported mental health and experience of violence among youth and young adults in Sweden. The results 
Table 3 Association (crude ORs, 95\% Cls) between mental health and violence among youth and young adults with samesex sexuality, in Sweden*

\begin{tabular}{llll}
\hline Same-sex sexuality & & & \\
\hline & All $(\mathrm{n}=318)$ & Male $(\mathrm{n}=100)$ & Female (n=217) \\
\hline $\begin{array}{l}\text { Mental health } \\
\text { High scores of depression }\end{array}$ & $1.7(1.36$ to 2.19$)$ & $1.8(1.32$ to 2.36$)$ & $1.8(1.32$ to 2.37$)$ \\
$\begin{array}{l}\text { High scores of anxiety } \\
\text { Violence }\end{array}$ & $1.8(1.43$ to 2.32$)$ & $1.4(0.91$ to 2.07$)$ & $2.0(1.50$ to 2.74$)$ \\
\hline $\begin{array}{l}\text { Experience of physical violence } \\
\text { Experience of sexual violence }\end{array}$ & $1.8(1.26$ to 2.49$)$ & $1.9(1.12$ to 3.25$)$ & $1.9(1.19$ to 2.91$)$ \\
\hline Experience of sexual coercion & $3.2(2.29$ to 4.37$)$ & $9.2(3.36$ to 25.35$)$ & $2.5(1.76$ to 3.58$)$ \\
\hline
\end{tabular}

Bold values indicate odds ratios at significance level $p \leq 0.05$.

indicate that among males with same-sex sexuality, $41.2 \%$ and $23.1 \%$ of the self-reported high scores of depression and anxiety, respectively, were attributable to their same-sex sexuality. This yielded PAF of $1.4 \%$ for high scores of depression and $0.8 \%$ for high scores of anxiety among male youth and young adults in Sweden. For females, $44.4 \%$ of both self-reported high scores of depression and anxiety were attributable to same-sex sexuality. This yielded a PAF of $3.3 \%$ for high scores of depression and anxiety among female youth and young adults in Sweden. Within the entire population, same-sex sexuality accounted for $4.7 \%$ and $4.1 \%$ of the self-reported experience of depression and anxiety, respectively, among youth and young adults in Sweden (table 5).

\section{Estimation of same-sex sexuality af of experience of violence}

Table 5 indicates that the same-sex sexuality AFs of violence within the entire population of young people were $4.5 \%$ for experience of physical violence, $7.3 \%$ for experience of sexual violence and $6.4 \%$ for experience of sexual coercion.

The AF of all three types of violence among males with experience of same-sex sexuality was relatively higher compared with that within the female group ( $\mathrm{AF}_{\text {Male vs }}$
Female; physical violence ( $50.0 \%$ vs $37.5 \%)$, sexual violence $(89.1 \%$ vs $58.3 \%)$, sexual coercion $(78.7 \%$ vs 50$))$. However, sPAF for all three types of violence assessed were higher within the general population of youth and young females due to the higher proportion of females with experience of same-sex sexuality in the study population ( $\mathrm{sPAF}$ Male vs Female; physical violence ( $1.7 \%$ vs $2.8 \%$ ), sexual violence $(3.0 \%$ vs $4.3 \%)$, sexual coercion $(2.7 \%$ vs 3.7)) (table 5).

\section{DISCUSSION}

The results of the study showed increased odds of poor mental health and experience of violence among youth and young adults with same-sex sexuality. However, different patterns were found between males and females when the analyses were stratified by gender. Males with same-sex sexuality had increased odds of high scores of depression, experience of physical and sexual violence and sexual coercion. Females with same-sex sexuality had increased odds of scoring high on depression and anxiety, experience of sexual violence and sexual coercion. Despite Sweden's rather proactive approach to the

Table 4 Multiple logistic regression analyses (OR, 95\% Cls) for mental health and violence among youth and young adults with same-sex sexuality, in Sweden*

\section{Same-sex sexuality}

\begin{tabular}{|c|c|c|c|}
\hline & All $(n=318)$ & Male $(n=100)$ & Female $(n=217)$ \\
\hline High scores of depression & 1.8 (1.39 to 2.26$)$ & 1.7 (1.11 to 2.58$)$ & $1.8(1.35$ to 2.47$)$ \\
\hline \multicolumn{4}{|l|}{ Violence } \\
\hline Experience of physical violence & $1.8(1.23$ to 2.51$)$ & $2.0(1.18$ to 3.46$)$ & 1.6 (0.98 to 2.54$)$ \\
\hline Experience of sexual coercion & 2.5 (1.95 to 3.30$)$ & 4.7 (2.94 to 7.57$)$ & 2.0 (1.45 to 2.68$)$ \\
\hline
\end{tabular}

Odds ratios for "All" are adjusted for age, gender and parental educational level. Odds ratios for "Male" and "Female" are adjusted for age and parental educational level. Bold values indicate odds ratios at significance level $p<0.05$. 
Table 5 Logistic regression-based attributable fraction (AF), stratum-specific population attributable fraction (sPAF) and overall population attributable fraction (PAF) of poor self-rated mental health and experience of violence among youth and young adults with same-sex sexuality, in Sweden

Attributable fraction among youth and young adults with same-sex sexuality group (AF), sPAF, overall Population Attributable Fraction (PAF), expressed in percentage

Outcome variable

\begin{tabular}{llll}
\hline Mental health & Male & Female & All \\
Overall PAF \% & AF (sPAF) \% & 4.7 \\
\hline High scores of depression & $41.2(1.4)$ & $44.4(3.3)$ & 4.1 \\
\hline High scores of anxiety & $23.1(0.8)$ & $44.4(3.3)$ & $3.5(2.8)$ \\
\hline $\begin{array}{l}\text { Violence } \\
\text { Experience of physical violence }\end{array}$ & $50.0(1.7)$ & 37.5 & 4.3 \\
Experience of sexual violence & $89.1(3.0)$ & $58.3(4.3)$ & 6.4 \\
\hline Experience of sexual coercion & $78.7(2.7)$ & $50.0(3.7)$ & 6.5 \\
\hline
\end{tabular}

rights and well-being of all citizens, including those with same-sex sexuality, these findings suggest that youth and young adults with same-sex sexuality still face a wide range of health challenges that need to be addressed.

\section{Mental health}

The findings suggest that youth and young adults with same-sex sexuality have increased risk of poor mental health, and these results are also in line with previous research findings from Sweden although these did not target younger age groups, except Donahue and colleagues who focused on adolescents. ${ }^{8} 915$ However, these studies also used different items in order to measure mental health status, and they also focused on either same-sex sexual behaviour or homosexual or bisexual identity, instead of the combined approach, same-sex sexuality, which was used in the current study. Despite these differences, the evidence of poor mental health among persons with same-sex sexuality is compelling, both in Sweden and globally. ${ }^{6}$ The findings from the current study corroborate existing research and suggest that there is an increased risk of experiencing depression and anxiety symptoms among people with same-sex sexuality in the age group of 18-30 years in Sweden.

Poor mental health among minority groups has previously been explained by the minority stress theory, which highlights stress factors associated with belonging to a minority group, such as stigma, prejudice, discrimination and internalised homophobia, and how these generate increased risks of poor mental health outcomes. ${ }^{32}$ Furthermore, individuals with same-sex sexuality perceive that they receive less emotional support from their family and friends-a critical factor for their mental health status. ${ }^{33}$ A Swedish study by Bränström ${ }^{8}$ found that younger homosexually and bisexually identified individuals in the age group 18-35 years lacked social support while the older age groups did not. Youth and young adults with same-sex sexuality might be exposed to particularly stressful situations during the exploration of their sexual orientation and 'coming out' processes, which tend to take place during this period in life. ${ }^{34}$ The awareness or feeling of being different from mainstream societal and cultural norms, and perhaps hiding and concealing these feelings due to the fear of negative reactions, would be expected to result in negative mental health outcomes. ${ }^{32}$

According to a multicountry study, conducted in the USA and Europe, the increased risk of poor mental health is of similar magnitude in countries with different attitudes towards same-sex sexuality. ${ }^{35}$ This indicates that the minority stress theory might not be the only explanation regarding the increased risk of poor mental health. Thus, there might be other, less explored factors, that contribute. Frisell $e t a l^{6}$ conducted a Swedish study on psychiatric morbidity associated with same-sex sexual behaviour that used twin controls, which confirmed that familial factors confounded the association between having same-sex experience and poor mental health.

Interestingly, some gender differences were found in the current study indicating a stronger association and effect of same-sex sexuality on anxiety among females. This finding concurs with other research findings. Gilman et $a l^{37}$ in their research on same-sex sexual behaviour and the life-time risk of getting diagnosed with depression or anxiety in the USA also found that females with same-sex sexuality had increased risk of depression and anxiety but not men with same-sex sexuality.

On the other hand, Björkenstam et at found a significantly increased risk of anxiety among homosexually or bisexually identified males in comparison with heterosexually identified males even though females were found to have the greatest risk. In line with this, a Dutch study found that homo- and bisexually identified females had a higher prevalence of poor mental health, even though homosexually and bisexually identified males were found to experience greater internalised homophobia, an important risk factor for poor mental health. ${ }^{38}$ Being open about one's sexual orientation has been found to be associated with improved mental health, although only among homosexual and bisexual 
identified females. ${ }^{38}$ This suggests that there might be various social and cultural factors at play that affect an individual's ability to be open about their sexual orientation. In Germany, in a study exploring attitudes towards males and females with same-sex sexuality, a total of $40 \%$ considered two males kissing in public as offensive, while only $13 \%$ considered two females kissing as offensive. ${ }^{39} \mathrm{~A}$ possible explanation could be differing attitudes towards males and females with gender atypicality as the gender role of males appears less flexible than the female gender role, resulting in greater exposure for males with gender atypicality as atypicality is more recognisable and unwelcomed. ${ }^{39} 40$ Encountering higher levels of negative reactions is likely to increases the risk of poor mental health among males with same-sex sexuality. ${ }^{38}$ Despite this, the findings from the current study could not demonstrate an increased risk of anxiety among males with same-sex sexuality, and a possible explanation could be the social construction of masculinity that impedes men from talking about mental health, as it might not be perceived manly to be, for example, anxious. ${ }^{41} 42$

\section{Violence}

In the current study, same-sex sexuality was independently associated with violence, both physical violence and sexual violence/coercion. These results are in line with the majority of previous studies from other settings. 15 17 43-45 The increased risk of physical violence among persons with same-sex sexuality also corresponds with research results from the Swedish context. ${ }^{81517}$ Bränström $^{8}$ found that the risk of experiencing physical violence and threats of assault was increased among 18-35year old bisexual females and homosexual males, but this risk, however, was not found in the age groups above 35 years. Limited research is available about sexual violence/coercion among youth and young adults in Sweden with same-sex sexuality, however, Donahue et $\mathrm{al}^{15}$ using twin heterosexual controls found that a higher percent $(53.2 \%)$ of non-heterosexual youth aged 18 reported experience of abuse, compared with heterosexual youth (35.3\%).

The increased exposure to violence might partly be explained by hate crimes against people with same-sex sexuality, as this violence specifically targets individuals due to their sexual orientation (perceived and actual). Yet, the perpetrator is not necessarily someone unknown but could be a close associate, as has been reported in such experiences. Moreover, research has also shown that intimate partner violence (IPV) is more common in same-sex relationships than heterosexual relationships. ${ }^{45}$ Exposure to minority stress factors has been identified as a crucial factor underlying increased risk of IPV in same-sex relationships. ${ }^{45}$ Furthermore, studies have shown that individuals with same-sex sexuality have increased risk of engaging in heavy drinking and substance abuse, which increases chances of aggravated aggression that could result in violence. ${ }^{6}$ Risky alcohol behaviour or substance abuse might also increase a person's vulnerability to violence, as both judgement and defence mechanisms are affected. Having poor mental health has also been identified as a risk factor for becoming a victim of violence. However, experience of violence is likely to increase the risk of poor mental health, and the nature of the causality might therefore be bidirectional. ${ }^{46}$

In the current study, we could establish an association between same-sex sexuality and having experienced physical violence among men only, where a larger effect was observed than among their female counterparts. This finding is supported by the findings of a meta-analysis that investigated victimisation experiences of LGBs. ${ }^{44} \mathrm{~A}$ possible explanation could be that males are generally over-represented in the statistics concerning of violence and more often the perpetrator of physical violence. Thus, males with same-sex sexuality might be more exposed to situations in which they incur physical violence due to their interest in other males.

The same-sex sexuality AFs for both poor self-reported mental health and experience of violence in this study give a clear indication of appreciable public health benefits $(4.1 \%-7.3 \%$ population risk reduction) of interventions targeted towards reducing the excess burden of poor mental health and violence among youth and young people with same-sex sexuality in Southern Sweden. It could be potentially beneficial to improve available sexual violence and poor mental health detection tools in public institutions within and outside of the healthcare system so as to ensure early detection of 'early warning signs of exposure to violence and poor mental health' among young people, with particular emphasis on same-sex sexuality youth. This could offer opportunities for targeted preventive interventions.

\section{Methodological considerations}

This was a cross-sectional study based on self-reported, retrospective information. As such, this creates a potential risk for recall bias, which could result in error due to misclassification of measured variables. Some items in the questionnaire referred to present experiences or recent exposure, for example, by specifying 'during the last 12 months', which could minimise the risk of recall error due to the shorter exposure period, ${ }^{47}$ but this was not the case for all items.

The response rate was $45 \%$, and although higher than in many current population surveys, this indicates that non-response rates merit due consideration. Possible reasons for non-response include lack of time, lack of sufficient Swedish language skills, or that the questions were considered to be too sensitive. However, based on the broad definition of same-sex sexuality and the survey instrument used in this study, we regard the non-response as likely to be non-differential with respect to the outcome and independent measures. Thus, we see no significant threat to the validity of the findings posed by selection bias.

Same-sex sexuality measured in this study included experience of same-sex sexual behaviour and homosexual or bisexual orientation in order to capture a broader group. 
However, individuals with experience of same-sex sexual behaviour may face challenges that are different from the challenges that those who identify as homosexual and bisexual face, and vice versa, which was not captured by using this broader term. These differences need to be explored further. Yet, when targeting a younger population, a broader term as the one used in this study might be important, as youth and young adults are in a period of development when they are exploring and finding out about who they are. Consequently, it might be difficult for younger person to accurately define their sexuality, which might not necessarily be congruent over time, thus necessitating the use of a measure that captures both identification and behaviour. ${ }^{48}$ A possible limitation is that the survey instrument did not include a specific question regarding same-sex sexual attraction. However, we regard the two measures, that is, same-sex sexual orientation and sexual relationships, as providing adequate indicators of same-sex sexuality, as sexual attraction in itself need not entail activities or behavioural aspects.

Mental health was measured by a previously validated self-rating instrument, HSCL-25. A high score of poor self-rated mental health, indicating symptoms of depression or anxiety, is not equivalent to fulfilling the criteria of a formal diagnosis. Furthermore, the day-to-day inconsistency of one's mental health state may influence the reliability of the results. Nevertheless, self-rating of symptoms provides an important indication of individuals' subjective perception of their mental health status. A limitation of the HSCL-25 is that it does not provide the basis for establishing clinical 'caseness' as such, as it is not a diagnostic instrument

The data were collected in 2013 and the associations explored might have changed during the last years. For example, acceptance of individuals with same-sex sexuality has been increasing in the Swedish context, which might improve the mental health issues observed, although studies based on more recent data are in line with results from the current study.

The proportion of female respondents in this study was slightly higher than male respondents, which could potentially affect the generalisability of the finding, although not to any appreciable extent. Although the findings of this study may be generalisable to similar populations nationally in Sweden and beyond, caution may be warranted to ensure that those populations have comparable context and demographic characteristics.

\section{CONCLUSION}

The findings of this study suggest that same-sex sexuality is associated with poor self-rated mental health and experience of violence among youth and young adults in Sweden. Some differences were observed between males and females, indicating that the vulnerabilities and experiences vary between young males and females. Further research is needed in order to gain a deeper knowledge of the factors underlying these associations and the gender differences observed. Such knowledge may be used to inform the design of preventive interventions and treatment programmes that target the unique health needs of this group, as well as to increase awareness among healthcare workers when meeting patients from this population.

Acknowledgements We would like to thank the participants who took the time to complete the survey.

Contributors CA developed the study design, analyzed and interpreted the data, and wrote the manuscript. BOA was involved in the analysis and interpretation of the data and in the preparation of the manuscript. TH was involved in the data analysis and interpretation of data and contributed to the writing of the manuscript. ML developed the study design, was involved in the data analysis, in the preparation of the manuscript and was acting as guarantor. All authors read and approved the final manuscript.

Funding This study received financial support from the Swedish National Public Health Agency under grant number 613/2011.

Competing interests None declared.

Patient and public involvement Patients and/or the public were not involved in the design, or conduct, or reporting, or dissemination plans of this research.

Patient consent for publication Not applicable.

Ethics approval The Regional Ethical Review Board in Lund, Sweden approved the study (Registration number 2012/353). Participants gave informed consent to participate in the study before taking part.

Provenance and peer review Not commissioned; externally peer reviewed.

Data availability statement № data are available. No additional data available.

Open access This is an open access article distributed in accordance with the Creative Commons Attribution Non Commercial (CC BY-NC 4.0) license, which permits others to distribute, remix, adapt, build upon this work non-commercially, and license their derivative works on different terms, provided the original work is properly cited, appropriate credit is given, any changes made indicated, and the use is non-commercial. See: http://creativecommons.org/licenses/by-nc/4.0/.

\section{ORCID iDs}

Charlotte Agardh http://orcid.org/0000-0002-1243-985X

Benedict Oppong Asamoah http://orcid.org/0000-0001-7308-1698

Tobias Herder http://orcid.org/0000-0002-8504-4031

\section{REFERENCES}

1 Bränström R, Pachankis JE. Sexual orientation disparities in the cooccurrence of substance use and psychological distress: a national population-based study (2008-2015). Soc Psychiatry Psychiatr Epidemiol 2018;53:403-12.

2 Thitasan A, Aytar O, Annerbäck E-M, et al. Young people's health and risk behaviours in relation to their sexual orientation: a crosssectional study of Thailand and Sweden. Sex Reprod Healthc 2019;21:67-74.

3 Priebe G, Svedin CG. Operationalization of three dimensions of sexual orientation in a national survey of late adolescents. J Sex Res 2013:50:727-38.

4 Tikkanen R, Abelsson J, et al, Göteborgs universitet, Institutionen för socialt a. UngKAB09: [kunskap, attityder och sexuella handlingar bland unga]: Inst. för socialt arbete, Göteborgs universitet, 2011.

5 Sexualitet och hälsa bland unga i Sverige : UngKAB15 - en studie om kunskap, attityder och beteende bland unga 16-29 år. Version 2 ed: Folkhälsomyndigheten 2017.

6 King M, Semlyen J, Tai SS, et al. A systematic review of mental disorder, suicide, and deliberate self harm in lesbian, gay and bisexual people. BMC Psychiatry 2008;8:70.

7 Plöderl M, Tremblay P. Mental health of sexual minorities. A systematic review. Int Rev Psychiatry 2015;27:367-85.

8 Bränström R. Minority stress factors as mediators of sexual orientation disparities in mental health treatment: a longitudinal population-based study. J Epidemiol Community Health 2017;71:446-52.

9 Björkenstam C, Björkenstam E, Andersson G, et al. Anxiety and depression among sexual minority women and men in Sweden: is 
the risk equally spread within the sexual minority population? $J$ Sex Med 2017;14:396-403.

10 Lucassen MFG, Stasiak K, Samra R, et al. Sexual minority youth and depressive symptoms or depressive disorder: a systematic review and meta-analysis of population-based studies. Aust N Z J Psychiatry 2017;51:774-87.

11 Meyer IH. Prejudice, social stress, and mental health in Lesbian, gay, and bisexual populations: conceptual issues and research evidence, 2003.

12 Blais M, Bergeron F-A, Duford J, et al. Health outcomes of sexual-minority youth in Canada: an overview. Adolesc Saude 2015;12:53-73.

13 Russell ST, Fish JN. Mental health in Lesbian, gay, bisexual, and transgender (LGBT) youth. Annu Rev Clin Psychol 2016;12:465-87.

14 Wichstrøm L, Hegna K. Sexual orientation and suicide attempt: a longitudinal study of the general Norwegian adolescent population. $J$ Abnorm Psychol 2003;112:144-51.

15 Donahue K, Långström N, Lundström S, et al. Familial factors, victimization, and psychological health among sexual minority adolescents in Sweden. Am J Public Health 2017;107:322-8.

16 Hatzenbuehler ML, Bränström R, Pachankis JE. Societal-level explanations for reductions in sexual orientation mental health disparities: results from a ten-year, population-based study in Sweden. Stigma Health 2018;3:16-26.

17 Bränström R, Hatzenbuehler ML, Pachankis JE. Sexual orientation disparities in physical health: age and gender effects in a populationbased study. Soc Psychiatry Psychiatr Epidemiol 2016;51:289-301.

18 The Public Health Agency of Sweden. Sexual and reproductive health and rights in Sweden 2017. Sweden, 2019.

19 Katz-Wise SL, Rosario M, Tsappis M, Lesbian TM. Lesbian, gay, bisexual, and transgender youth and family acceptance. Pediatr Clin North Am 2016:63:1011-25.

20 Hall WJ. Psychosocial risk and protective factors for depression among Lesbian, gay, bisexual, and Queer youth: a systematic review. $J$ Homosex 2018;65:263-316.

21 Blondeel K, de Vasconcelos S, García-Moreno C, et al. Violence motivated by perception of sexual orientation and gender identity: a systematic review. Bull World Health Organ 2018;96:29-41.

22 Nationellt centrum för kvinnofrid N. Nationellt centrum för kvinnofrid N. Våld mot hbtw -personer - en forsknings-och kunskapsöersikt. Uppsala universitet, 2018.

23 Forsberg M. Brunettes and Blondes, youth and sexuality in multi cultural Sweden. Gothenburg: University of Gothenburg, 2005.

24 Nettelbladt P, Hansson L, Stefansson CG, et al. Test characteristics of the Hopkins symptom check List-25 (HSCL-25) in Sweden, using the present state examination (PSE-9) as a caseness criterion. Soc Psychiatry Psychiatr Epidemiol 1993;28:130-3.

25 World Health Assembly. Youth and health risks. WHA64.28 ED: World Health organization, 2011. Available: https://apps.who.int/iris/handle/ $10665 / 3594$

26 UN General Assembly. Implementation of the world programme of action for youth to the year 2000 and beyond: United nations, 2001. Available: https://undocs.org/A/56/180

27 Dubow EF, Boxer P, Huesmann LR. Long-term Effects of Parents' Education on Children's Educational and Occupational Success: Mediation by Family Interactions, Child Aggression, and Teenage Aspirations. Merrill Palmer Q 2009;55:224-49.

28 Derogatis LR, Lipman RS, Rickels K, et al. The Hopkins symptom checklist (HSCL): a self-report symptom inventory. Behav Sci 1974;19:1-15.
29 Lewin B, Fugl-Meyer K, Helmius G. Sex in Sweden; on sexual life in Sweden 1996: public health agency of Sweden 1998.

30 Agardh A, Odberg-Pettersson K, Östergren P-O. Experience of sexual coercion and risky sexual behavior among Ugandan university students. BMC Public Health 2011:11:527.

31 Larsson M, Ross MW, Tumwine G, et al. Determinants of unmet needs for healthcare and sexual health counselling among Ugandan university students with same-sex sexuality experience. Glob Health Action 2016;9:30790-90.

32 Prejudice $\mathrm{MIH}$. Social stress, and mental health in lesbian, gay, and bisexual populations: conceptual issues and research evidence. Psychological Bulletin 2003;129:674-97.

33 Jorm AF, Korten AE, Rodgers B, et al. Sexual orientation and mental health: results from a community survey of young and middle - aged adults. British Journal of Psychiatry 2002;180:423-7.

34 Rosario M, Schrimshaw EW, Hunter J. Predicting different patterns of sexual identity development over time among Lesbian, gay, and bisexual youths: a cluster analytic approach. Am J Community Psychol 2008;42:266-82.

35 Lewis NM. Mental health in sexual minorities: recent indicators, trends, and their relationships to place in North America and Europe. Health Place 2009;15:1029-45.

36 Frisell $\mathrm{T}$, Lichtenstein $\mathrm{P}$, Rahman $\mathrm{Q}$, et al. Psychiatric morbidity associated with same-sex sexual behaviour: influence of minority stress and familial factors. Psychol Med 2010;40:315-24.

37 Gilman SE, Cochran SD, Mays VM, et al. Risk of psychiatric disorders among individuals reporting same-sex sexual partners in the National comorbidity survey. Am J Public Health 2001:91:933-9.

38 Kuyper L, Fokkema T. Minority stress and mental health among Dutch LGBs: examination of differences between sex and sexual orientation. J Couns Psychol 2011;58:222-33.

39 Keuzenkamp S. More and more normal, but never normal: the Hague, Netherlands: social and cultural planning office, 2010.

40 Kane EW. "No Way My Boys Are Going to Be Like That!": Parents' Responses to Children's Gender Nonconformity. Gender \& Society 2006;20:149-76.

41 Keohane A, Richardson N. Negotiating gender norms to support men in psychological distress. Am J Mens Health 2018;12:160-71.

42 Verdonk P, Seesing H, de Rijk A. Doing masculinity, not doing health? A qualitative study among Dutch male employees about health beliefs and workplace physical activity. BMC Public Health 2010;10:712.

43 Graham LM, Jensen TM, Givens AD, et al. Intimate partner violence among same-sex couples in college: a propensity score analysis. $J$ Interpers Violence 2019;34:1583-610.

44 Katz-Wise SL, Hyde JS. Victimization experiences of Lesbian, gay, and bisexual individuals: a meta-analysis. The Journal of Sex Research 2012;49:142-67.

45 Edwards KM, Sylaska KM, Neal AM. Intimate partner violence among sexual minority populations: a critical review of the literature and agenda for future research. Psychol Violence 2015;5:112-21.

46 Campbell JC. Health consequences of intimate partner violence. The Lancet 2002;359:1331-6.

47 Althubaiti A. Information bias in health research: definition, pitfalls, and adjustment methods. J Multidiscip Healthc 2016;2016:211-7.

48 Saewyc EM, Bauer GR, Skay CL, et al. Measuring sexual orientation in adolescent health surveys: evaluation of eight school-based surveys. J Adolesc Health 2004;35:345.e1-345.e15 